\title{
Anatomical Study of Foramen Ovale and Foramen Spinosum in the Norma Basalis with Clinical Correlation
}

\section{Varalakshmi KL ${ }^{1 *}$, Jyothi Nayak ${ }^{2}$ and Sangeeta $\mathbf{M}^{\mathbf{3}}$}

${ }^{1}$ Professor, Department of Anatomy, MVJ Medical College and Research Hospital,

Hoskote, Bangalore, India

${ }^{2}$ Lecturer, Department of Anatomy, DAPM RV Dental College, Bangalore, India

${ }^{3}$ Professor and HOD, Department of Anatomy, MVJ Medical College and Research

Hospital, Hoskote, Bangalore, India

*Corresponding Author: Varalakshmi KL, Professor, Department of Anatomy, MVJ

Medical College and Research Hospital, Hoskote, Bangalore, India.

DOI: 10.31080/ASOR.2022.05.0424
Received: October 27, 2021

Published: February 18, 2022

(C) All rights are reserved by Varalakshmi KL., et al.

\section{Abstract}

Background: The greater wing of sphenoid bone in norma basalis shows two important foramina: foramen ovale and foramen spinosum. Anatomical study of foramen ovale is of great diagnostic importance in trigeminal rhizotomy and transfacial fine needle aspiration techniques. Foramen spinosum is an important foramen used for neurosurgical procedures of infratemporal and middle cranial fossa.

Materials and Methods: A total 90 dry adult human skulls obtained from MVJ Medical College and Research Hospital were used for the study. The anteroposterior diameter (length) and mediolateral diameter (transverse) of both foramen ovale and foramen spinosum were measured. The shape of foramen ovale and spinosum were noted and data obtained were analyzed statistically.

Results: The mean length of foramen ovale on right side was $7.07 \mathrm{~mm}$ and on the left side was $7.09 \mathrm{~mm}$. The mean breadth on right side was $4.81 \mathrm{~mm}$ and on the left side was $5.52 \mathrm{~mm}$. Oval shape was the most predominant type on both sides The mean length of foramen spinosum on right side was $2.66 \mathrm{~mm}$ and on the left side was $2.58 \mathrm{~mm}$. The mean breadth on right side was $1.42 \mathrm{~mm}$ and on the left side was $1.64 \mathrm{~mm}$. Round shape of foramen spinosum was common on both sides.

Conclusion: The findings of present study will be of great value for neurosurgeons, radiologists and neurologists for planning and management of surgeries of middle cranial fossa and infratemporal fossa.

Keywords: Trigeminal Rhizotomy; Foramen Ovale; Foramen Spinosum; Middle Cranial Fossa; Infratemporal Fossa

\section{Introduction}

Norma basalis is a complex part of skull extending from central incisor anteriorly to superior nuchal line of occipital bone posteriorly. It is pierced by numerous foramen which transmits important neurovascular structures [1]. Infratemporal surface of greater wing of sphenoid contains two important foramina i.e. foramen ovale and foramen spinosum. Foramen ovale as the name suggests oval in shape transmits mandibular division of trigeminal nerve, accessory meningeal artery, lesser petrosal nerve and emis- sary vein connecting the pterygoid venous plexus with cavernous sinus. Foramen ovale appears as discrete foramen by 22 weeks of gestation and by seventh month of intrauterine life it forms a ring shaped foramen [2]. It is situated at the transition zone between intra cranial and extracranial structures and involved in numerous diagnostic as well as surgical procedures [3]. Foramen ovale provides access for percutaneous trigeminal rhizotomy, a microvascular decompression surgery used in the treatment of trigeminal neuralgia [4]. The main cause of trigeminal neuralgia is entrap- 
ment of mandibular nerve as it passes through the foramen ovale. In case of cavernous sinus tumors, foramen ovale is a commonly used route for percutaneous diagnostic biopsy with good accuracy [5]. Foramen Vesalius or emissary sphenoidal foramen is an inconstant foramen present in middle cranial fossa located anteromedial to foramen ovale and it connects the pterygoid venous plexus with cavernous sinus [6].

Foramen spinosum small round foramen located posterolateral to foramen ovale transmits middle meningeal artery, middle meningeal vein and nervous spinosum. The ring-shaped development of foramen spinosum completes after 8th month of birth and it may extend up to 7 years after birth. In microsurgical procedures involving middle cranial fossa and infratemporal fossa, foramen spinosum forms an important landmark due to its proximity to other foramens. It is clinically important in middle meningeal artery graft surgeries such as bypass surgery between middle meningeal artery and internal carotid artery or posterior cerebral artery [7]. Precise topographical knowledge of foramen spinosum is important in identifying and putting ligature to torn middle meningeal vessels in fracture of base of skull [8].

Hence the present study is an attempt to give a detailed morphologic and morphometric features of foramen ovale and foramen spinosum as well as foramen Vesalius, as it would be of great help to neurologist, radiologist and neurosurgeons for planning and management of surgeries involving the above foramina.

\section{Materials and Methods}

The present study was conducted on 90 dry skulls of unknown sex and age, obtained from the department of anatomy, MVJ Medical college and Research Hospital, Bangalore, Karnataka. The posterior part of greater wing of sphenoid bone was observed carefully for the presence of foramen ovale and foramen spinosum. The patency of both the foraminsa are checked by passing probe trough both the foramina. Damaged skulls or damaged foramen were excluded from the study. All measurements were taken on bilaterally with the help of digital vernier caliper of $0.01 \mathrm{~mm}$ accuracy by two different persons. The anteroposterior diameter (length) and mediolateral diameter (transverse) of both foramen ovale and foramen spinosum were measured.
The data obtained were analyzed statistically. Mean and standard deviation were calculated. The shape of both foramen ovale and foramen spinosum were noted. The percentage of each shape was calculated.

\section{Results}

The study was conducted on 180 foramina from 90 dried skulls. The morphological and morphometric features of foramen ovale and spinosum were studied.

\section{Foramen ovale}

\section{Shape of foramen ovale}

In the current study, four different shapes of foramen ovale were observed-oval, round, irregular and almond (Right side-oval-59, round-22, irregular-7, almond-2. On left side-oval-49, round-34, irregular-4, almond-3). The most common shape on both the sides were oval followed by round and almond shape was least common on both sides.

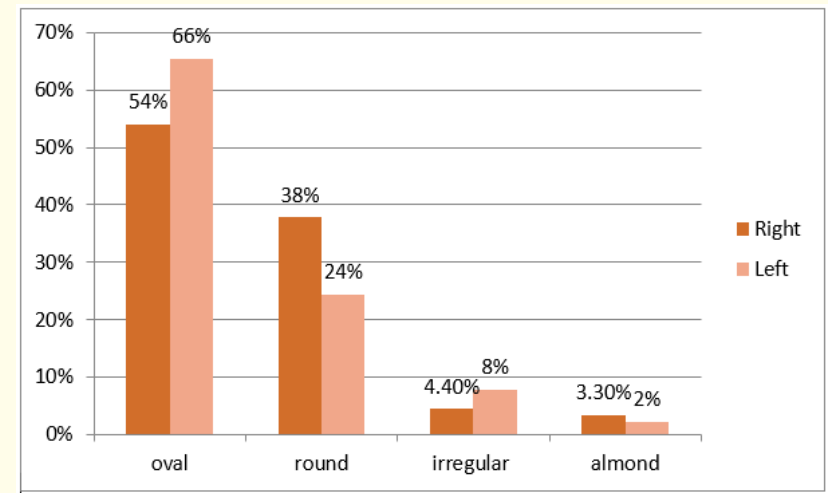

Graph 1: Showing the percentage of different shapes of foramen ovale on right and left sides.

\section{Diameter of foramen ovale}

The mean length of foramen ovale on right side was $7.07 \mathrm{~mm}$ and on the left side was $7.09 \mathrm{~mm}$. The mean breadth on right side was $4.81 \mathrm{~mm}$ ad on the left side was $5.52 \mathrm{~mm}$. 

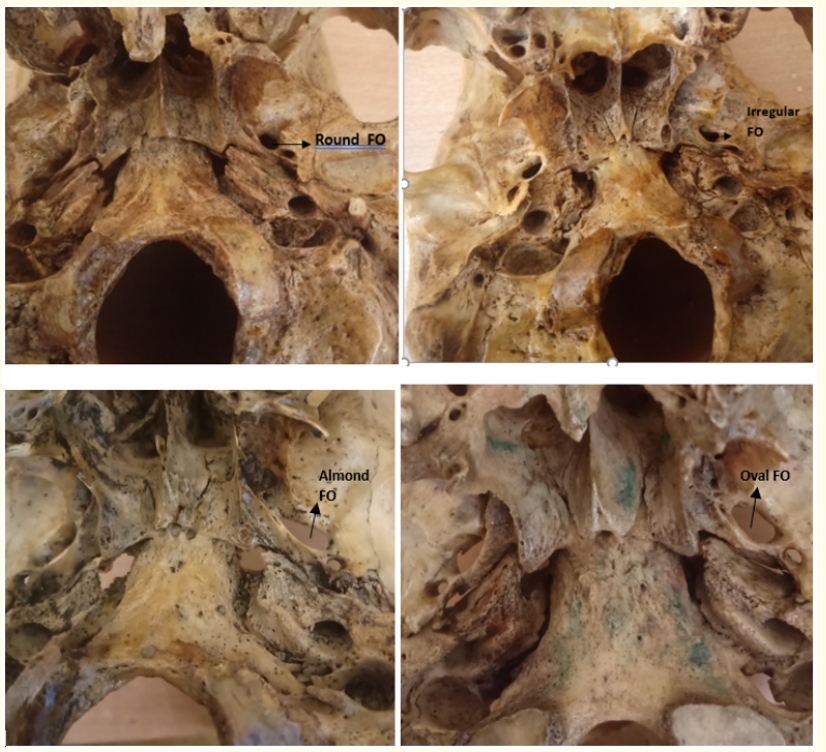

Figure 1: Showing different shapes (round, irregular, almond and oval) of foramen ovale (FO).

\begin{tabular}{|c|c|c|c|c|}
\hline & \multicolumn{2}{|c|}{$\begin{array}{c}\text { Anteroposterior } \\
\text { diameter (in mm) }\end{array}$} & \multicolumn{2}{|c|}{$\begin{array}{c}\text { Transverse diameter } \\
\text { (in mm) }\end{array}$} \\
\hline & Right & Left & Right & Left \\
\hline Mean & 7.07 & 7.09 & 4.81 & 5.52 \\
\hline Standard deviation & 1.03 & 0.57 & 1.02 & 1.07 \\
\hline Minimum & 3.99 & 5.05 & 2.39 & 3.83 \\
\hline Maximum & 8.79 & 8.05 & 6.97 & 7.57 \\
\hline
\end{tabular}

Table 1: Showing the anteroposterior diameter (length) and transverse diameter (breadth) of foramen ovale.

\section{Foramen spinosum}

Shape of foramen spinosum: In the present study 3 different shapes of foramen spinosum was observed-round, oval, irregular (Right-round-54, oval-34, irregular-2. On left side-round-47, oval39 , irregular-4) Round shape was common on both sides.

\section{Diameter of foramen spinosum}

The mean length of foramen spinosum on right side was 2.66 $\mathrm{mm}$ and on the left side was $2.58 \mathrm{~mm}$. The mean breadth on right side was $1.42 \mathrm{~mm}$ and on the left side was $1.64 \mathrm{~mm}$.

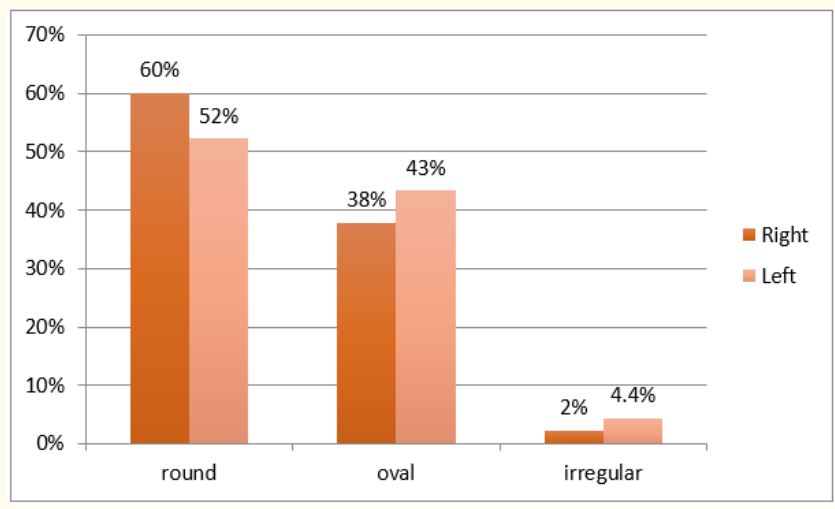

Graph 2: Showing the percentage of different shapes of foramen spinosum on right and left sides.
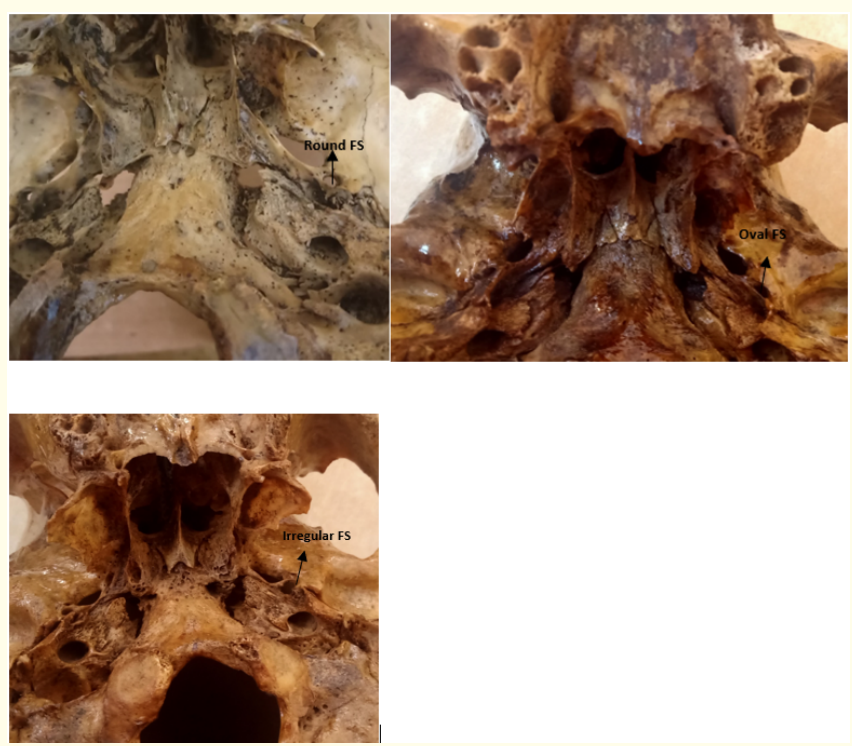

Figure 2: Showing different shapes (round, irregular and oval) of foramen spinosum (FS).

\section{Presence of foramen vesalius}

Foramen Vesalius was present medial to foramen ovale seen in 6 skulls ( 4 on right side and 2 on left side).

\section{Discussion}

The variations in the cranial foramen in term of location, number, size not only leads to insight towards evolution it is also of 


\begin{tabular}{|c|c|c|c|c|}
\hline \multirow{2}{*}{ Parameter } & \multicolumn{2}{|c|}{$\begin{array}{c}\text { Anteroposterior } \\
\text { diameter (in mm) }\end{array}$} & $\begin{array}{c}\text { Transverse diameter } \\
\text { (in mm) }\end{array}$ \\
\cline { 2 - 5 } & Right & Left & Right & Left \\
\hline Mean & 2.66 & 2.58 & 1.42 & 1.64 \\
\hline Standard deviation & 0.71 & 0.78 & 0.32 & 0.30 \\
\hline Minimum & 1.09 & 1.6 & 1.06 & 1.04 \\
\hline Maximum & 4.31 & 5.46 & 1.96 & 2.10 \\
\hline
\end{tabular}

Table 2: Showing the anteroposterior diameter (length) and transverse diameter (breadth) of foramen spinosum.

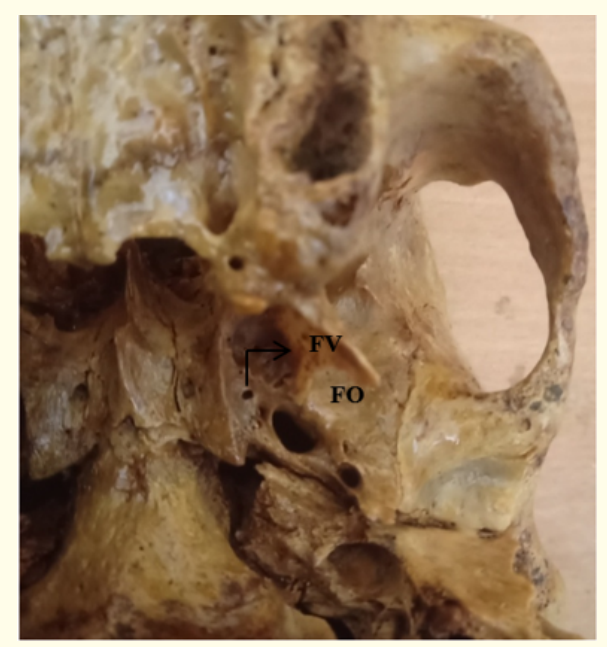

Figure 3

great clinical significance. The variations in the foramen help the clinicians to interpret the radiographs correctly and helps in performing surgical procedures efficiently avoiding the complications [9]. Foramen ovale is an oval opening situated in the posterior part of greater wing of sphenoid one. It has body (basisphenoid), lesser wings (orbit sphenoid) and greater wings (alisphenoid). Sphenoid bone shows intramembranous and endochondral ossification. The ossification of sphenoid bone extends from posterior to anterior part. A CT scan study was conducted on fetus with 22 weeks 3 days gestational age showed ossification of alisphenoid and in that study the foramen ovale was appeared as a large defect [10]. Endochondral part differentiates as cartilage surrounding the mandibular branch of trigeminal nerve forming foramen ovale occurs later [11]. In new born the mean length of foramen ovale is about 3.85 $\mathrm{mm}$ and in adult it is $7.2 \mathrm{~mm}$ and transverse diameter in new born is $1.81 \mathrm{~mm}$ and in adults it is $3.7 \mathrm{~mm}$ [12].
The knowledge of shapes of foramen ovale is important in procedures to reach the trigeminal ganglion or sensory root through the foramen as in case of trigeminal rhizotomy. According to Lindblom and Henderson the venous asymmetry of emissary vein which passes through the foramen ovale, connecting the cavernous sinus with that of pterygoid venous plexus account for the variations in the size and shape of the foramen [9]. The electroencephalographic analysis of seizures by placing electrode at foramen ovale gives the best neurophysiological information especially in patients undergoing selective amygdalohippocampectomy surgeries [13]. It is one of the main foramen used in the CT guided trans facial fine needle aspiration to diagnose squamous cell carcinoma, meningioma and gives access to biopsy of deeper regions [14].

In the present study ovale shaped foramen ovale was more predominant followed by round, irregular and almond shaped was least. In a study conducted by Meera., et al. on 30 skulls oval shape was more predominant followed by round and almond. The study also showed the presence of slit shaped and pear-shaped foramen and irregular shape foramen was not seen their study [15]. Magi Murugan., et al. conducted study on 250 skulls and observed that the foramen was oval in $69 \%$ skulls, almond shaped in $29 \%$ of skulls and round in $2 \%$ of skulls [14].

Majority of studies on shape of foramen ovale (Anju., et al. Roma Patel., et al. [16,17]) showed oval shape was more common followed by almond, round and slit shape whereas the results of our study is slightly different from the others. According to Hauser and De Stefao these cranial variants are mainly due to epigenetic factors which mainly occurs as a product of genetically determined growth processes of other tissues such as muscles, nerves, vessels which is affecting the bone formation [9].

The mean length of foramen ovale on right side was $7.07 \pm 1.03$ $\mathrm{mm}$ and on the left side was $7.09 \pm 0.57 \mathrm{~mm}$. The mean breadth on right side was $4.81 \mathrm{~mm} \pm 1.02$ and on the left side was $5.52 \pm 1.07$ $\mathrm{mm}$. Somesh., et al. conducted study on 83 dry skulls and mean length of foramen ovale on the right side was $7.64 \pm 1.19 \mathrm{~mm}$ and on the lefts side it was $7.56 \pm 1.12 \mathrm{~mm}$. The mean width on the right side was $5.128 \pm 0.82 \mathrm{MM}$ and on the left side was $5.24 \pm 0.95$ mm [12]. Study by Jyotsna Patil., et al. on 52 dry skulls showed the mean length of foramen ovale on right side was $7.02 \pm 2.17 \mathrm{~mm}$ ad on the left side $6.8 \pm 1.40 \mathrm{~mm}$. The width on right side was $5.0 \pm$ 
$0.42 \mathrm{~mm}$ and $4.70 \pm 0.91 \mathrm{~mm}$ on left side [5]. Biswabina ray., et al. conducted morphometric study on 35 dry skulls and the anteroposterior diameter on the right and left side was $7.46 \pm 1.41 \mathrm{~mm}$ and $7.01 \pm 1.41 \mathrm{~mm}$ respectively. The width on right and left side was $3.21 \pm 1.02 \mathrm{~mm}$ and $3.29 \pm 0.85 \mathrm{~mm}$ respectively [18]. Study conducted in New York on fluoroscopically assisted laser targeting of the foramen ovale showed mean length of foramen ovale on right side is $6.9 \mathrm{~mm}$ and $6.8 \mathrm{~mm}$ on left side. The mean width on right side was $3.4 \mathrm{~mm}$ and on the left side was $3.8 \mathrm{~mm}$ [12].

Sometimes foramen ovale may be narrowed or in growing spicules of bone divide it into compartments; the anterior portion of divided foramen is called as Foramen of Vesalius or emissary sphenoidal foramen. This emissary sphenoidal foramen is located 2-3 $\mathrm{mm}$ anterior to the foramen ovale and it reflects the one of the most important characteristics of human being that is the expression of variation in the differentiation of crania venous outlets as it is not seen in any other primates [19]. In the present study foramen Vesalius was present unilaterally in 6 skulls. Many studies have been conducted in the past to promote the better understanding of the morphology of its structure and also to emphasize its clinical importance as it transmits emissary vein which is the common route for the transmission of extracranial infection to the intracranial part [6].

Foramen spinosum is also an important foramen of middle cranial fossa, first described in $18^{\text {th }}$ century by Jacob Benignus, a Danish anatomist. Since it lies close to spine of greater wing of sphenoid, he named it so. Variations in the shape of foramen spinosum has been mentioned in the literature from time to time. These variations may be due to variation in the origin, course and branching pattern of middle meningeal artery or due to incomplete osteogenesis [8]. The morphological knowledge of foramen spinosum is important in interpretation of radiological findings.Present study showed 3 different shapes of foramen spinosum: the most common shape on both the side was round (56\%) followed by oval (40.5\%) and irregular (3.3\%). Vanitha., et al. conducted a morphometric study on 58 dry skulls and observed that round shape was seen in $51.79 \%$, oval in $32.14 \%$ and irregular in $16.07 \%$ [8]. A study by Jeyanthi., et al. on 50 dry skulls showed $55 \%$ of round, oval in $40 \%$, irregular in $2 \%$ and they also observed pinhole shape in remaining $3 \%$ of skulls [20]. Shaik Hussain Saheb., et al. conducted study on 300 skulls and found round shape in 58\%, oval in 38\% and irregu- lar in $4 \%$ of skulls. The results of these study correlate with finding of our study [21].

In the present study mean length of foramen spinosum on right side was $2.66 \mathrm{~mm}$ and on the left side was $2.58 \mathrm{~mm}$. The mean breadth on right side was $1.42 \mathrm{~mm}$ and on the left side was 1.64 $\mathrm{mm}$. In a study conducted by Vanitha., et al. The mean anteroposterior and Transverse diameter of the foramen spinosum on right side was found to be 2.262 and $2.029 \mathrm{~mm}$ respectively and on left side it was 2.418 and $2.0316 \mathrm{~mm}$ respectively. The mean anteroposterior and transverse diameter of the foramen spinosum on right side was found to be 2.262 and $2.029 \mathrm{~mm}$ and on left side it was 2.418 and $2.0316 \mathrm{~mm}$ respectively. Punitha., et al. conducted study on 100 dry skulls and the anteroposterior diameter on the right side was $2.48 \mathrm{~mm}$ and on the lefts side $2.52 \mathrm{~mm}$ and transverse diameter on the right and left side was $1.29 \mathrm{~mm}$ and $1.44 \mathrm{~mm}$ respectively [4].

\section{Conclusion}

The comprehensive knowledge of morphology and morphometry of foramen ovale and foramen spinosum is of immense value to neurosurgeons while performing diagnostic and surgical procedures. Detailed knowledge of variations in these foramina will help to differentiate abnormal foramina from normal during computed tomography and magnetic resonance imaging.

Hence foramen ovale is clinically significant in neurosurgical procedures like administration of anaesthesia through mandibular, treatment of trigeminal neuralgia and treatment of cases involving cavernous sinus. Similarly, foramen spinosum is of immense clinical importance to radiologist and neurosurgeons in diagnosing and interpreting any aneurysms or vascular lesions in cranial cavity.

\section{Bibliography}

1. Deepa AR and Sandeep GB. "A Morphometric analysis of foramen ovale and foramen spinosum of human sphenoid bone in the South Gujarat population: Vital for Medical Practitioners in cases of Trigeminal Neuralgia". Journal of Advance Researches in Biological Sciences 4.3 (2012): 243-245.

2. WJ Hamilton and HW Mossman. "Hamilton, Boyd and Massman's Human Embryology-prenatal development of form and function". $4^{\text {th }}$ Edition (1972): 532-538. 
3. Khairnar KK., et al. "Foramen ovale and foramen pinosum: Amorphometric study". Anatomica Karnataka 6 (2012): 68-72.

4. Rani P. "Morphological and morphometric study of foramen ovale and foramen spinosum in adult human dry skulls". Master thesis, Madras Medical College, Chennai.

5. Patil J., et al. "The foramen ovale morphometry of sphenoid bone in South Indian population". Journal of Clinical and Diagnostic Research 7.12 (2013): 2668-2670.

6. Nayak G and Pradhan S. "Anatomical study of foramen Vesalius". Journal of Evolution of Medical and Dental Sciences 7.35 (2018): 3847.

7. Tewari S., et al. "Morphometric analysis of foramen spinosum in South Indian population". Acta Medica Iraica 56.02 (2017): 113-118.

8. Gupta V., et al. "Morphometric ad morphological analysis of foramen spinosum in North Indian human skulls". International Journal of Scientific Research 8.9 (2019): 8-10.

9. Raj SM., et al. "Morphometric and topographic study of foramen ovale in Indian skulls". Malaysian Journal of Medical and Biological Sciences 3 (2016): 75-84.

10. Gupta N, et al. "Foramen ovale-Morphometry and its surgical importance". Innovative Journal of Medical and Health Sciences (2013): 4-6.

11. Somesh MS., et al. "An anatomical study of foramen spinosum in South Indian dry Skulls with emphasis on morphology and morphometry". International Journal of Anatomy and Research 3 (2015): 1034-1038.

12. Somesh MS., et al. "A morphometric study of foramen ovale". Turkish Neurosurgery 21.3 (2011): 378-383.

13. Wieser HG and Siegel AM. "Analysis of foramen ovale electrode-recorded seizures and correlation with outcome following amygdalohippocampectomy". Epilepsia 32 (1991): 838850 .
14. Murugan M and Hussain SS. "Morphometric and morphological study of foramen ovale". International Journal of Anatomy and Research 2.4 (2014): 664-667.

15. Jacob M., et al. "Morphometry of foramen ovale and its Clinical significance". International Journal of Current Research 5.7 (2013): 1963-1964.

16. Anju L R., et al. "Anatomical variations of foramen spinosum". Innovative Journal of Medical and Health Science 2.5 (2012): 86-88.

17. Patel R and Mehta CD. "Morphometry of foramen ovale at base of skull in Gujarat". IOSR Journal of Dental and Medical Sciences 13.6 (2014): 26-30.

18. Ray B., et al. "Anatomic variations of foramen ovale". Kathmandu University Medical Journal 3 (2005): 64-68.

19. Mamatha Y and Thilak NT. "Foramina of alisphenoid - A morphological and morphometric study in adult dry skull of South Indian Population". Innovative Publication (2015): 273-275.

20. Krisnamurhty J.

21. Hussain SS., et al. "Morphological and morphometric study of foramen spinosum". International Journal of Anatomy and Research 5.4.1 (2017): 4523-4526.

\section{Assets from publication with us}

- Prompt Acknowledgement after receiving the article

- Thorough Double blinded peer review

- Rapid Publication

- Issue of Publication Certificate

- High visibility of your Published work

Website: www.actascientific.com/

Submit Article: www.actascientific.com/submission.php

Email us: editor@actascientific.com

Contact us: +919182824667 